\title{
A REALIDADE CIVIL DOS HAITIANOS E SENEGALESES NO BRASIL Uma análise da vivência destes imigrantes em solo brasileiro
}

\author{
Camila Gomes da Silva ${ }^{1}$ \\ Paula Tressoldi ${ }^{2}$ \\ Everton Ricardo Bootz ${ }^{3}$
}

\begin{abstract}
RESUMO: O presente artigo tem como objetivo analisar aspectos e características como: educação, trabalho, moradia, ou seja, a vivência e estadia de imigrantes Haitianos e Senegaleses em solo brasileiro. Para tanto, o estudo se sedimentou em uma pesquisa de campo, na qual se entrevistou dezesseis imigrantes, entre Haitianos e Senegaleses, a fim de compreender como têm vivido no Brasil e se adaptado aos costumes e leis brasileiras. Assim, os resultados obtidos através da pesquisa realizada demonstram os maiores problemas enfrentados por este povo, bem como a insucesso da vinda para o Brasil, em busca de melhores salários e situações adequadas de trabalho.
\end{abstract}

Palavras-chave: Imigrante. Legalização. Protocolo. Haitiano. Senegalês.

RESUME: This article aims to analyze aspects and characteristics as: education, labor work, housing, the living and housing of the Haitian and Senegalese immigrants, in Brazil. So, the study was concretized through a field research, which incorporates 16 interviews. It objectives to analyzes how these immigrants have been lived and adapted to the costumes and as to the Brazilian Law. The results of this research show the problems under which they have suffered as well the failure of coming to Brazil, in search for better salaries and work.

Keywords: Immigrant. Legalization. Protocol. Haitian. Senegalese.

\section{INTRODUÇÃO}

O presente artigo versa sobre a vivência dos imigrantes senegaleses e haitianos em solo brasileiro. O tema merece um estudo aprofundado, tendo em vista o grande volume da imigração desses países no Brasil, segundo dados do IBGE ingressam em território brasileiro cerca de cinquenta a cem haitianos por dia. ${ }^{4}$

\footnotetext{
${ }^{1}$ Acadêmica do Curso de Direito, da UNICNEC.

${ }^{2}$ Acadêmica do Curso de Direito, da UNICNEC.

${ }_{4}^{3}$ Professor Dr. do Curso de Direito da UNICNEC.

4 [s/n]. Imigração haitiana no Brasil. IN: Wikipédia, [s/l], 2015. Disponível em: <https://pt.wikipedia.org/wiki/Imigra\%C3\%A7\%C3\%A3o_haitiana_no_Brasil>. Acesso em: 25 ago. 2016. Cf: "O ano de 2010 marcou o início da imigração haitiana no Brasil. A entrada dos haitianos via Tabatinga, no Amazonas, começou a ser notada em fevereiro de 2010, logo após o terremoto, que sacudiu violentamente o Haiti, e em particular a capital, Porto Príncipe. A catástrofe provocou a
} 
É importante a verificação sobre a vinda para o Brasil, quase sempre clandestina, bem como os meios pelos quais esses povos constroem suas vidas em um novo país, uma vez que a Constituição Federal de 1988, no art. 5o, estabelece que brasileiros e estrangeiros tenham resguardados os mesmo direitos e vivam sob as mesmas regras. Este estudo objetiva esclarecer pontos importantes sobre a vida civil dos imigrantes. Ao longo do trabalho são explorados aspectos importantes como: legalização do estado de imigrantes, interação com o povo anfitrião, preconceitos e demais experiências agradáveis/desagradáveis vividas.

O trabalho é elaborado através de uma pesquisa de campo, na qual foram entrevistados imigrantes senegaleses e haitianos, fonte na qual são obtidas informações importantes acerca do meio de vida destes no Brasil. Estas entrevistas revelam aspectos civis relacionados a estes imigrantes em solo brasileiro; para tanto, tomar-se-á como marco inicial da análise os direitos constitucionais garantidos aos estrangeiros e o Estatuto do Estrangeiro (Lei 6.815/80).

As entrevistas são fruto de uma Pesquisa Acadêmica, promovida pelo Instituto de Ensino Superior - Faculdades Cenecista de Osório (FACOS/CNEC), Rio Grande do Sul. A Pesquisa teve duração de um ano, destrinchada em quatro fases: a primeira fase ocorreu em fins de 2015 e se deteve na seleção e leitura bibliográfica (3 meses). A segunda fase foi a coleta dos dados, durante a qual as entrevistas foram realizadas em três cidades da região norte litorânea do RS: Tramandaí, Osório e Capão da Canoa (3 meses). Com os dados em mãos, teve início a terceira fase: a sistematização dos dados coletados no verão de 2016 (3 meses). Com os dados sistematizados, dois artigos foram redigidos, na quarta $\mathbf{e}$ última fase, retratando os resultados da pesquisa (3 meses). Este artigo é um deles.

morte de mais de 150 mil pessoas e deixou cerca de 300 mil deslocados internos. A presença de haitianos no Brasil era quantitativamente inexpressiva até então. Segundo dados do IBGE, em 1940 viviam no Brasil 16 haitianos; em 1950 - 21; em 1960 -159; em 1970 - 90; em 1980 - 127; em 1991 - 141; em 2000 - 15; e em 2010 - 36 pessoas. Com a presença no Haiti da Missão das Nações Unidas para a Estabilização do Haiti - MINUSTAH, comandada pelo Brasil desde 2004, os haitianos passaram a ver o Brasil como um ponto de referência. Após o terremoto de 2010, que desencadeou uma grande onda de emigração no Haiti, o Brasil passou a ser um dos destinos preferenciais dos migrantes, dada a dificuldade de entrada nos países de emigração tradicional (Estados Unidos, Canadá, República Dominicana, França, etc.). Atualmente cerca de 50 a 100 haitianos entram por dia no Brasil de maneira indocumentada, pelo estado do Acre." 
O grupo de pesquisa se compôs de cinco estudantes (dentre estes, dois bolsistas e três voluntários) e um professor orientador.

Houve três grupos específicos de entrevistados, quais sejam: um grupo de sete imigrantes, em Tramandaí (todos senegaleses); outro grupo de sete integrantes em Osório (cinco senegaleses e dois haitianos); o terceiro grupo é de Capão da Canoa, composto por dois imigrantes senegaleses. Assim, o universo de pesquisa se restringiu às entrevistas de dezesseis (16) imigrantes, sendo quatorze (14) senegaleses e dois (2) haitianos. As entrevistas foram gravadas e depois transcritas, sendo os nomes dos entrevistados resguardados, neste artigo, mediante o recurso do codinome.

O tema da pesquisa é: O MERCADO NEGRO - A realidade política e de trabalho dos senegaleses e haitianos na região litorânea norte do Rio Grande do Sul. Como o material foi abundante tanto quanto ao aspecto civil quanto trabalhista, foi resolvido traduzir os resultados da pesquisa em dois artigos, sendo um ressaltando o aspecto trabalhista e o segundo, os civis. Este artigo retrata os aspectos civis deste esforço acadêmico.

O artigo é estruturado em quatro tópicos compreendidos em conceituação dos direitos constitucionais garantidos aos estrangeiros; o senegalês e o haitiano em solo brasileiro, onde são abordados aspectos como a rota e a situação destes enquanto imigrantes; a forma de legalização dos imigrantes nos órgãos brasileiros; por fim, os aspectos cíveis destes imigrantes no Brasil, revelados pelas entrevistas.

\section{DOS DIREITOS CONSTITUCIONAIS GARANTIDOS AOS ESTRANGEIROS}

A Declaração Universal dos Direitos Humanos - DUDH (1948), a qual foi proclamada pela Assembleia Geral das Nações Unidas, determina que: "todos os homens nascem iguais em dignidade, e garante de maneira unânime direitos sem distinção de raça, cor, sexo, língua, opinião política ou qualquer outra condição"5.

${ }^{5}$ LECH, Marcelo Mendes; MOREIRA, Luiz Carlos Lopes. Manual de Direito Internacional. 1. ed. Porto Alegre: Editora Ulbra, 2004, p.15. 
Pelo fato do Brasil ser membro da ONU, incorporou a DUDH à sua Constituição, como reza o $2^{\circ}$ e $3^{\circ}$ parágrafos, do art. 5ำ da CF/88.

$\S 2^{\circ}$ Os direitos e garantias expressos nesta Constituição não excluem outros decorrentes do regime e dos princípios por ela adotados, ou dos tratados internacionais em que a República Federativa do Brasil seja parte. $\S 3^{\circ}$ Os tratados e convenções internacionais sobre direitos humanos que forem aprovados, em cada Casa do Congresso Nacional, em dois turnos, por três quintos dos votos dos respectivos membros, serão equivalentes às emendas constitucionais.

Para a CF brasileira, 'estrangeiro' é todo aquele que nasceu fora do território brasileiro e não obteve nacionalidade brasileira ${ }^{6}$. Ao estrangeiro que esteja sob a jurisdição brasileira é assegurado os mesmos direitos de que gozam os brasileiros. A Constituição Federal, lei maior brasileira, em seu artigo. 5, caput, afirma que os direitos fundamentais são assegurados aos "brasileiros e estrangeiros residentes no País" (grifo nosso).

Diante do caráter humanitário implícito na Constituição Federal, alinhada às convenções internacionais, é assegurado aos estrangeiros direitos quanto à dignidade da pessoa humana. Esta garantia independe do estado deste em solo brasileiro, seja por ter visto de trânsito, de turista, temporário, permanente, de cortesia, oficial ou diplomático. ${ }^{7} \mathrm{Na}$ mesma esteira, aos estrangeiros, são garantidos os direitos basilares como: saúde, educação, moradia, trabalho remunerado, segurança, liberdade de locomoção, liberdade para atividade religiosa, privacidade, dentre outros que regem a vida civil também dos brasileiros.

Ou seja, aos estrangeiros são garantidos todos os direitos fundamentais, como se brasileiros fossem; porém, o mesmo não se aplica aos direitos sociais, como por exemplo, impetrar ação popular, uma vez que somente o cidadão brasileiro pode se utilizar da referida ferramenta jurídica. Outras limitações constitucionais são: aquisição de propriedades rurais (art. 190), remessa de lucro ao exterior (art. 172), pesquisa e lavra de recursos minerais (art. 176, parágrafo 1ํ), propriedade de empresa jornalística e de radiodifusão sonora e de sons e imagens

${ }^{6}$ LUFT, Celso Pedro. Minidicionário LUFT. 23. ed. São Paulo: Editora Ática, 2013, p. 305. Cf: "es.tran.gei.ro adj 1. Originário ( pessoa ou coisa) de outro país em relação àquele a que se pertence.S.m.2. Indivíduo originário de outro país. 3. País diferente daquele a que se pertence."

${ }^{7}$ Art. 4을 da Lei N.ㅇ 6.815 de 19 de agosto de 1980 - Estatuto do Estrangeiro. 
(art. 222). Por fim, aos estrangeiros, salvo quando naturalizados, é igualmente vedado os direitos políticos, quais sejam, os de votar, serem votados $^{8}$ ou participarem como membros filiados de partidos políticos.

\section{SENEGALESES E HAITIANOS EM SOLO BRASILEIRO}

A imigração senegalesa e haitiana no Brasil ganhou força em meados de 2011, após o terremoto que devastou a capital Haitiana, Porto Príncipe. Com o país devastado, a população haitiana, na sua grande maioria homens, rumou ao Brasil em busca de trabalho para custear o sustento da família deixada em seu país de origem ${ }^{9}$.

O Brasil, que não esperava a entrada em massa dos imigrantes haitianos e senegaleses, teve que improvisar acomodações, trabalho, documentos de legalização aos imigrantes. Mesmo após quase seis anos do início da imigração haitiana e senegalesa ao Brasil, este serviço assistencial ainda é precário, motivo pelo qual os imigrantes sofrem com a desigualdade, preconceito, ausência de assistência, ficando a mercê da própria sorte.

\subsection{Rota de Imigração: do alto custo e do risco durante a trajetória}

A pesquisa de campo aponta que a porta de entrada brasileira aos imigrantes haitianos e senegaleses se dá através do Acre. O trajeto entre o ponto de partida, Senegal ou Haiti, até o Estado Brasileiro é feito por avião ou navio. O tempo gasto no percurso é de aproximadamente quinze dias e quase sempre de forma

\footnotetext{
${ }_{9}^{8}$ Art. 14, parágrafo $2^{\circ}$, da Constituição Federal de 1988.

$9 \quad[\mathrm{~s} / \mathrm{n}]$, Sismo do Haiti de 2010. IN: Wikipédia, [s/d]. Disponível em: <https://pt.wikipedia.org/wiki/Sismo_do_Haiti_de_2010>. Acesso em: 14 ago. 2016. Cf: "O sismo do Haiti de 2010 foi um terremoto catastrófico que teve seu epicentro na parte oriental da península de Tiburon, a cerca de $25 \mathrm{~km}$ da capital haitiana, Porto Príncipe, foi registrado às $16 \mathrm{~h} 53 \mathrm{~m} 10 \mathrm{~s}$ do horário local (21h53m10s UTC), na terça-feira, 12 de janeiro de 2010. O abalo alcançou a magnitude 7,0 $\mathrm{M}_{\mathrm{w}}$ e ocorreu a uma profundidade de $10 \mathrm{~km}$ (6,2 mi). O Serviço Geológico dos Estados Unidos registrou uma série de pelo menos 33 réplicas sismológicas, 14 das quais eram de magnitude $5,0 \mathrm{M}_{\mathrm{w}}$ a $5,9 \mathrm{M}_{\mathrm{w}}$. O Comitê Internacional da Cruz Vermelha estima que cerca de três milhões de pessoas foram afetadas pelo sismo; o Ministro do Interior do Haiti, Paul Antoine Bien-Aimé, antecipou em 15 de janeiro que o desastre teria tido como consequência a morte de 100000 a 200000 pessoas."
}

\section{DIREITO, CULTURA E CIDADANIA


clandestina, o que torna a viagem arriscada e onerosa. Um entrevistado assim se expressa: "Por que é muito difícil, quando vem de Senegal pelo Equador, tem reserva no hotel, entra pelo Acre". Das quinze entrevistas, treze mencionaram que a entrada se deu pelo Acre. Isto dá um percentual de 87\%. Depois do Acre, eles seguem para São Paulo e daí são disseminados pelo país, a partir das possibilidades de trabalho nas diferentes regiões.

No recorte abaixo, é expresso a história de sua chegada ao Brasil. São sete imigrantes senegaleses de Tramandaí:

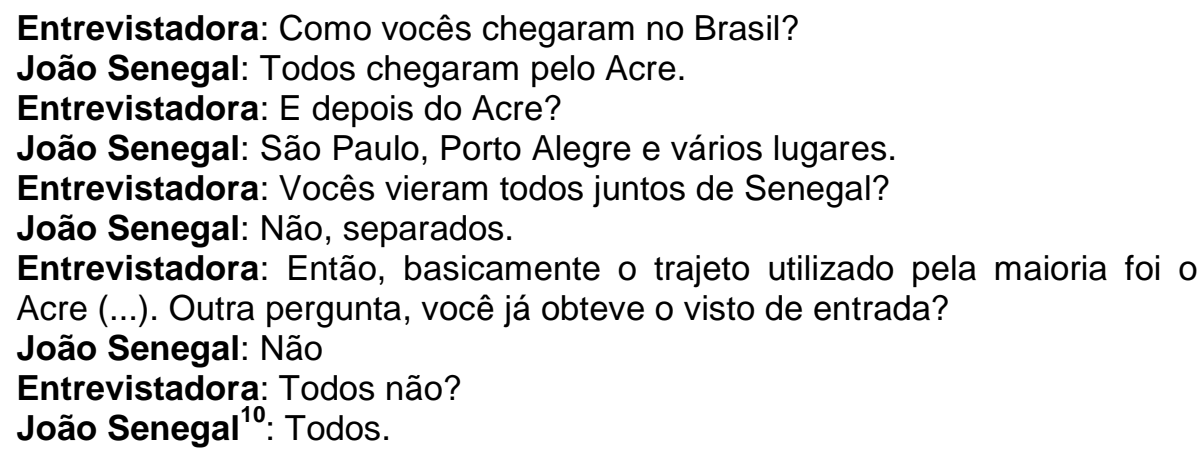

O risco e o alto custo são os aspectos mais apontados entre os entrevistados, como razão de não retorno ao país de origem. $40 \%$ dos entrevistados, sequer conseguiram, até o momento da entrevista, adquirir o valor gasto no trajeto de vinda, muito menos, enviar dinheiro à família no país de origem. As entrevistas demonstraram a deficiência dos países de origem, como o Haiti e o Senegal; $60 \%$ logram enviar mensalmente alguma quantia ao país de origem. Essas remessas são a garantia de sustento e de sobrevivência dos familiares que ficaram à espera desse dinheiro.

Com o ingresso em solo brasileiro, os destinos são quase sempre os mesmos, Porto Alegre, no Estado do Rio Grande do Sul, Blumenau, em Santa Catarina, e São Paulo. O que torna essas três capitais o destino dos imigrantes é o grande número de indústrias. Há uma carência de mão de obra nestas cidades, além da existência de "comunidades imigrantes", facilitando a adaptação dos recém-

${ }^{10}$ Como o entrevistado 2 sabia melhor o português, ele traduzia a fala dos outros entrevistados e acabava por falar mais do que os outros. A comunicação entre eles era majoritariamente na língua nativa. 
chegados. É possível perceber o despreparo do Brasil em receber os imigrantes (seja com o ensino da língua, alojamentos, regulamentação de documentos). A impossibilidade de absorver a mão de obra ofertada pelos imigrantes é percebida nas entrevistas. Caso o país estivesse preparado para a chegada, poder-se-ia encaminhar os imigrantes para todo o território brasileiro, fomentando o trabalho em todas as regiões, incentivando a economia e auxiliando os estrangeiros.

\section{A LEGALIZAÇÃO DO HAITIANO E SENEGALES}

O advento da Resolução n. ${ }^{\circ}$ 97, do $\mathrm{CNIg}^{11}$, em 30 de outubro de 2015, através da política brasileira da Embaixada Brasileira em Porto Príncipe, na qual restou estabelecida a possibilidade de emissão de visto ao imigrante ainda na capital de Porto Príncipe, facilitou o ingresso de haitianos em solo brasileiro. Atualmente, o imigrante já sai de seu país de origem portando o documento necessário para sua identificação ${ }^{12}$.

Mas antes era diferente. Em 2011, quando chegaram ao Brasil em grande número, os imigrantes encontraram um país anfitrião despreparado. Com a chegada em massa dos imigrantes haitianos e, posteriormente dos senegaleses, surgiram óbices quanto à legalização da estadia em território brasileiro. Inicialmente eram concedidos vistos de turista, válidos apenas por trinta dias. O visto de turista é concedido apenas para motivos recreativos ou para visita (art. 9ํㅡ, Lei 6.815/80). Destarte, o visto de turista não possibilita a emissão de Carteira de Trabalho, documento fundamental para que o imigrante possa exercer atividade laboral de maneira legal e usufrua de todos os benefícios trazidos por ela (férias e folgas remuneradas, auxílio desemprego, entre outros).

${ }^{11}$ [s/n], CNIg prorroga concessão de visto humanitário aos haitianos. IN: Ministério do Trabalho, Brasília, 4 out. 2015. Disponível em: <http://trabalho.gov.br/noticias/1029-cnig-prorroga-concessaode-visto-humanitario-aos-haitianos>. Acesso em: 25 ago. 2016.

${ }_{12}$ [s/n]. VISTO HUMANITÁRIO PERMANENTE (VIPER Humanitário) E VISTO PERMANENTE A TÍTULO DE REUNIÃO FAMILIAR. IN: Embaixada do Brasil em Porto Príncipe. Disponível em: $<$ http://portoprincipe.itamaraty.gov.br/pt-br/visto_permanente_humanitario_para_haitianos.xml>. 
Este recorte da entrevista realizada em Tramandaí demonstra os problemas relacionados à ausência de visto adequado:

Entrevistadora: $O$ fato de não ter visto, quais as consequências negativas? João Senegal: Por que é muito ruim, não tem dinheiro pra passagem e dormi dois meses na rua.

Entrevistadora: Quais são os documentos necessários que você sabe que precisa?

João Senegal: Agora não tenho RG, tenho CPF e o protocolo foi pedido. (...)

Entrevistadora: Quais são os aspectos positivos de ter o visto? Por que vocês querem o visto? O que vai trazer de bom? Quais são as vantagens de ter o visto?

João Senegal: Tem problema para habitação; aqui tem gente boa; eu trabalhei numa empresa, mas agora mandaram embora. Problema pro trabalho com carteira assinada; os africanos sempre têm problemas.

Com a necessidade de estabelecer vínculos mais duradouros entre os imigrantes e a indústria brasileira, o Estado brasileiro passou a conceder o 'visto permanente', com caráter humanitário, com o qual se é possível emitir da CTPS ${ }^{13}$. A Resolução Normativa no 97, de 2012, sancionada para os casos haitianos, legitima a emissão de 'vistos permanentes' (art. 4º, IV c/c art. 16ss, Lei 6.815/80), baseando-se no Tratado Internacional de 1951, do qual o Brasil é signatário. Este Tratado defende os direitos de permanência em país estrangeiros por imigrantes que procuram refúgio, em decorrência de guerra ou perseguição política.

${ }^{13}$ Cf. [s/n], Haitianos formam filas no Ministério do Trabalho para legalização na capital. IN: AC24HORAS, Rio Branco/AC, 14 maio 2014. Disponível em: <http://www.ac24horas.com/2014/05/14/haitianos-formam-filas-no-ministerio-do-trabalho-para-

legalizacao-na-capital/?doing_wp_cron $=1475607273.8897490501403808593750>$. Acesso em: 25 ago. 2016. Cf: "Diversos haitianos e senegaleses formam filas na Delegacia do Ministério do Trabalho e Emprego no Acre nesta quarta-feira (14) em busca de informações e a expedição da carteira de trabalho. Desde o terremoto que destruiu parte do Haiti e matou mais de 300 mil pessoas em 2010, o governo brasileiro concede visto de permanência, em caráter humanitário. Grupos de haitianos chegam ao País atravessando a fronteira pelo Acre. Mas, por causa das cheias que atingiram o Estado no começo do ano, o governo acreano fechou um abrigo para esses imigrantes e tem custeado passagens de ônibus com destino à São Paulo. Os imigrantes chegam ao Brasil em busca de emprego. Os haitianos que passaram a morar no Brasil têm acesso a uma cartilha do Ministério do Trabalho e Emprego para conseguir trabalho. O Guia de Informações sobre Trabalho aos Haitianos, organizado de acordo com perguntas e respostas sobre temas específicos, está publicado tanto em português quanto em crioulo haitiano na página do Ministério do Trabalho na internet. Estão disponíveis orientações sobre direitos trabalhistas, Carteira de Trabalho, assinatura e rescisão de contratos de trabalho e de experiência, aviso prévio, sindicalização, entre outros temas. Dúvidas podem ser esclarecidas pelos e-mails: conselho.imigracao@mte.gov.br e imdh@migrante.org.br. Os haitianos que devem seguir as orientações são os que têm permissão para ficar no Brasil por meio de concessão de refúgio e os que obtiveram visto de residência permanente na embaixada brasileira em Porto Príncipe, capital do Haiti." 
Art. 1 Ao nacional do Haiti poderá ser concedido o visto permanente previsto no art. 16 da Lei $n^{\circ} 6.815$, de 19 de agosto de 1980, por razões humanitárias, condicionado ao prazo de 5 (cinco) anos, nos termos do art. 18 da mesma Lei, circunstância que constará da Cédula de Identidade do Estrangeiro.

Esta decisão está em sintonia com os desejos dos imigrantes: a de trabalhar. Ao mesmo tempo, está em sintonia igualmente com a política de desenvolvimento econômico brasileiro, posto oferecer mão de obra aos diferentes setores da economia nacional. $\mathrm{O}$ art. 16, em seu parágrafo único reza:

Parágrafo único. A imigração objetivará, primordialmente, propiciar mão-de-obra especializada aos vários setores da economia nacional, visando à Política Nacional de Desenvolvimento em todos os aspectos e, em especial, ao aumento da produtividade, à assimilação de tecnologia e à captação de recursos para setores específicos. (grifo)

Esta mão especializada é encontrada nas entrevistas, pois muitos imigrantes têm formação especializada. Mas ao contrário do esperado pelo Estatuto do Estrangeiro, todas estas especializações não são aproveitadas, posto todos os entrevistados trabalharem em outras atividades, que não as de suas formações profissionais de origem. Dizem que não há condições pela falta da carteira de trabalho. O próximo recorte expressa esta realidade de mal aproveitamento da mão de obra:

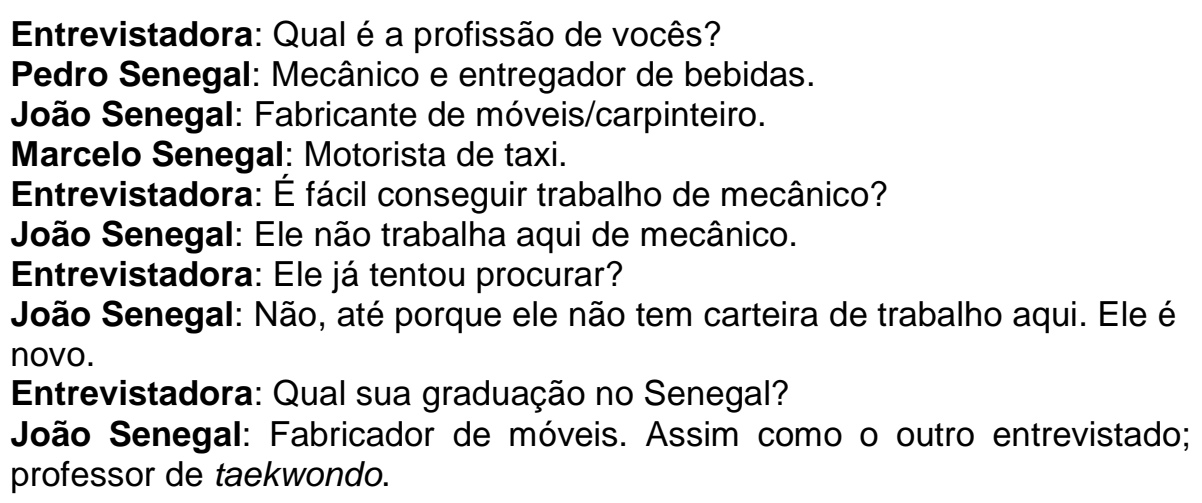

\section{A VIDA CIVIL DOS IMIGRANTES HAITIANOS E SENEGALESES NO BRASIL}

Ao longo da análise dos resultados e dados da pesquisa de campo elaborada como fundamento basilar da elaboração deste artigo, possibilitou extrair 
alguns aspectos comuns a todos os imigrantes Senegaleses e Haitianos, os quais serão explanados a seguir. Como já mencionado neste artigo, ao chegarem ao Brasil, os imigrantes encontraram, e até hoje encontram, um país despreparado: eles chegam sem falar português, sem um destino, sem local para hospedar-se e sem emprego garantido. Por tudo isto, vivem em alojamentos precários, trabalhos irregulares (muitas vezes como vendedores ambulantes nas ruas), longe da rede de educação e saúde.

\subsection{Língua e moradia}

Para ter o mínimo de conforto e segurança, os Senegaleses e Haitianos procuram alojar-se com outros imigrantes que já se encontram há mais tempo no Brasil, posto falarem melhor o português e por estarem acostumados à cultura brasileira. Isto facilita a vida no Brasil, seja com a tradução do idioma, maior obstáculo aos recém-chegados, seja pela busca de emprego. Um entrevistado menciona este fato: "Quando ligo para um amigo que está no Paraná, ele fala que não é normal, não, porque teve uma pessoa que chegou aqui no Brasil e ele não fala português, as pessoas sempre tratam muito".

O simples fato de se ter um endereço, um domicilio, viabiliza a obtenção de documentos, por exemplo. Este aspecto está presente na pesquisa: os novos imigrantes buscam auxílio, primeiramente, junto aos conterrâneos; depois, junto aos órgãos federais. Esta busca por unidade é consequência de uma cultura de solidariedade. Existe um senso de solidariedade muito forte entre os imigrantes senegaleses. Na entrevista realizada com sete deles, foi forte a menção e à prática da solidariedade. No recorte abaixo é possível perceber este senso de solidariedade:

João Senegal: Nossa cultura lá no Senegal, todo mundo que vai para outro país todo mundo tem juntado um familiar, não importa se mora em outra parte do Senegal, eu vou olhar ele e ele a mim, nós temos solidariedade.

Marcelo Senegal: Ajudar sempre.

Entrevistadora: só pelo olhar.

João Senegal: Nós fazemos o olhar solidário.

Marcelo Senegal: É o ajudar, por exemplo, se você é Senegalês igual a nós.

Entrevistadora: Por isso que aqui, nessa situação difícil no Brasil, vocês também praticam essa solidariedade?

Todos: E. 
Neste recorte, percebe-se que a solidariedade entre os imigrantes é própria da cultura senegalesa. Este cuidado pelo outro é vivenciado no Senegal, como revela a entrevista. Lá também há problemas, haja vista terem imigrado a procura de melhores condições de trabalho e de vida. Ao aportarem no Brasil, este 'olhar' que cuida do outro se torna um recurso importante, em meio às dificuldades como língua e moradia. Eles se unem para se protegerem e se cuidarem. A moradia passa a ser um espaço que mantém o conterrâneo perto do 'olhar'. Ao final do recorte, quando a entrevistadora pergunta se esta prática de solidariedade é realizada aqui no Brasil, 'todos' respondem afirmativamente. Ou seja, mesmo aquele que está a mais tempo ou mesmo que no país de origem não se conhecessem, aqui passam a tratar a todos com um cuidado solidário.

Esta solidariedade é exemplificada também no âmbito do trabalho. No caso do grupo de Tramandaí, todos trabalham na informalidade, vendendo produtos comprados em São Paulo e revendidos nas ruas e praças da cidade litorânea. Eles trabalham em conjunto, apoiando-se mutuamente na compra e venda dos produtos. Procuram estar juntos nas ruas e nas praias, durante o verão. No mínimo em dois.

No grupo de Osório também há demonstração deste senso de solidariedade. Neste grupo também há sete entrevistados, sendo cinco senegaleses e dois haitianos, morando todos numa mesma residência. Quando os entrevistadores chegaram na casa deles, dois estavam na varanda, um cortando o cabelo do outro. Também há a prática de empréstimo de créditos para que pudessem se comunicar com seus familiares nos países de origem. No caso do trabalho, todos trabalham com carteira assinada, num restaurante da região. Mas se há alguma reclamação por parte do empregador, então o grupo se une para uma defesa mais contundente.

Houve um episódio singular, no qual um dos senegaleses foi demitido do emprego, tendo que se mudar para Porto Alegre. Para ajudar o conterrâneo, outro senegalês se demitiu para poder ir junto com o primeiro, a fim de protegê-lo, já que mal falava português, ao contrário do segundo. Esta solidariedade tem como fator explicativo também a cultura religiosa muçulmana, como ver-se-á mais adiante. Antes, abordar-se-á o tema do trabalho. 


\subsection{Trabalho}

Diariamente centenas de imigrantes rumam ao Brasil em busca de um trabalho que lhes proporcione uma vida digna, ou então, do qual seja possível custear a sobrevivência sua e da família. Porém, esta realidade não é encontrada no Brasil. O que encontram é um alto índice de desemprego, consequência da forte crise que atinge a economia, afeta os cidadãos brasileiros e, consequentemente, os imigrantes.

Essa situação se agrava ainda mais frente ao problema de legalização do imigrante em solo brasileiro. O haitiano ou o senegalês muitas vezes está de posse apenas do Protocolo, concedido pela Policial Federal, que é o 'visto de permanência', de valor humanitário. Com isto, ele fica de mãos atadas para buscar novos horizontes, como por exemplo, a emissão de Carteira de Trabalho.

Com base na pesquisa realizada, foi identificado que, em sua maioria, os senegaleses/haitianos trabalham exercendo outras funções daquelas desempenhadas em seu país de origem, como relatado anteriormente. No Brasil, estes laboram com vendas, no mercado informal, como vendedores ambulantes; apenas três, dos dezessete entrevistados, estavam trabalhando com carteira assinada.

O Ministério do Trabalho e Emprego, órgão fiscalizador da mão de obra brasileira, em parceira com a Justiça do Trabalho e Ministério Público do Trabalho, atua no combate ao trabalho ilegal dos imigrantes. Estes órgãos atuam como "pontes" entre os empregadores e os imigrantes. Aqueles desejam ofertar vagas aos imigrantes, mas não sabem a maneira correta de o fazer; estes almejam um trabalho digno, mas têm receios acerca da garantia de seus direitos.

O Ministério do Trabalho e Emprego - MET - desenvolveu, em seu site, informações relacionadas ao trabalho estrangeiro; ou seja, é possível ao empregador sanar duvidas básicas, em consulta aos artigos publicados, e até mesmo enviar questões diretamente ao órgão. Também é possível ao imigrante 
também tomar ciência de oficinas de qualificação e idiomas ofertados em várias regiões do Brasil, bem como dos direitos que lhes são resguardos. ${ }^{14}$

A atuação destes órgãos, no combate ao trabalho ilegal e até mesmo ao abuso da mão de obra imigrante, é de suma importância, tendo em vista o caráter de desigualdade de conhecimento e auxílio pelo qual os imigrantes se encontram. A título de exemplo, é possível citar o trecho da fala do imigrante, o qual declara que foi demitido sem que tivesse sido pago o que the cabia, e que muitas vezes era tratado com indiferença, tanto pela chefia como pelos colegas de trabalho, o que gerava um desconforto em suas atividades.

\begin{abstract}
Entrevistadora: Vocês têm reclamações?
João Senegal: Problema de discriminação dentro da empresa, pois os brasileiros ganhavam melhor e possuíam mais privilégios. Já nós trabalhávamos mais e ganhávamos menos enquanto os brasileiros trabalhavam menos e ganhavam mais. Tínhamos problemas para receber nosso salário. Quando a empresa começou a demitir os primeiros a serem demitidos foram os senegaleses, sem direito a nada, e nos retiram da casa onde morávamos.
\end{abstract}

\title{
5.3 Educação, costumes e religião
}

Quando questionados se desejam trazer suas famílias para o Brasil, poucos se manifestaram positivamente. Os demais, disseram que não, fundamentando que - Brasil é apenas ponto de passagem para aferirem determinado montante e retornaram ao país de origem. Os imigrantes acrescentaram, ainda, que os costumes brasileiros são muito diferentes dos seus de origem, pelo que sofrem para adaptar-se e que a família também sofreria.

O grupo de Tramandaí externou o desejo de trazer os familiares, quando oportuno. Mas o grupo de Osório, disse que não desejam trazer os familiares pela cultura permissiva brasileira. Por serem muçulmanos, os valores da cultura brasileira agridem fortemente seus próprios valores de vida e religiosidade. Não desejam ver seus filhos crescendo num ambiente com valores tão destoantes dos de sua

${ }^{14}$ MILESI, Rosita; TRAVIESO, Emilio (Org.). GUIA DE INFORMAÇÃO SOBRE TRABALHO AOS HAITIANOS. IN: CIBAI MIGRAÇÕES, $2012 . \quad$ Disponível em: <http://www.cibaimigracoes.com.br/arquivos/guia_sobre_trabalho_aos_haitianos.pdf>. Acesso em: 25 ago. 2016. 
religiosidade. Dos todos os entrevistados que possuem família no país de origem, quatro têm filhos, sendo que destes quatro: dois não pretendem trazer seus filhos para o Brasil, haja vista pretenderem constituir nova família aqui; o terceiro não pretende trazer seus filhos para o Brasil pelo fator cultural; e o quarto diz querer trazer seus filhos para o Brasil apenas se conseguir trabalho.

O contato com os familiares nos países de origem permanece intenso, a despeito de viverem em meio à sociedade brasileira. Esta prática reflete um costume comum entre os imigrantes, que diariamente se comunicam com familiares no exterior. Esses familiares são mães e pais, como também esposas e filhos. Contudo, mesmo casados e com filhos, sua religião não os impede de constituir nova família aqui no Brasil, como atesta esta fala:

Pedro Senegal: É muito boa para mim a vida em Senegal, pois tenho familiares, tenho tudo. Aqui também é muito bom para mim, tenho trabalho, oportunidades. (...) Quero encontrar uma família por aqui, pois se tem família fico; outras oportunidades surgem (risos).

\section{CONSIDERAÇÕES FINAIS}

Com a elaboração do presente trabalho de pesquisa acadêmica, produziu-se entendimento quanto a vivência do povo haitiano e senegalês enquanto imigrante no Brasil. A Constituição Federal Brasileira, com condão humanitário, assevera que, aos estrangeiros, serão garantidos os mesmos direitos que aos brasileiros. No art. 5은 elenca os direitos fundamentais a todo cidadão que esteja sob sua tutela, estendendo-os também aos estrangeiros.

Em que pese existirem direitos constitucionais garantidos, os imigrantes encontram uma realidade diversa da almejada. Ao longo da pesquisa foi possível perceber que o país anfitrião pouco se preocupa com a sina dos imigrantes, fornecendo apenas a documentação legal básica.

Diante do quadro caótico que estes imigrantes encontram, procuram seus pares para viver em grupo, seja como meio de comunicar-se ou de obter um emprego, uma vez que o Estado não fornece nem um nem outro. Ao longo da pesquisa, características como: união, companheirismo e solidariedade se 
sobressaíram nas entrevistas, transmitindo a ideia de que a união é o único meio de sobrevivência em um país tão "diferente".

Em busca de trabalho, os imigrantes não conseguem exercer as mesmas atividades que exerciam em sua terra natal, acabando por exercer tarefas mais simples, resultando em uma remuneração igualmente mais baixa. A despeito disso, sempre que possível, o dinheiro obtido é enviado aos familiares no país de origem, pouco ficando em solo brasileiro. O que fica, é gasto com utilidades básicas como: moradia (aluguel, ou diárias em pousadas), alimentação, aparelhos telefônicos e internet.

Em um país que passa por uma forte crise, a mão de obra imigrante poderia ser uma saída para fomentar o mercado de trabalho. Porém, segundo a pesquisa, essa mão de obra não chega até a indústria, que carece dela. Quase todos os entrevistados tiveram ou têm problemas em trabalhar para empresas, seja pela falta de qualificação, dificuldade com o idioma, o que poderia ser facilmente sanado caso houvesse, por parte da União, um programa que qualificasse estes imigrantes, encaminhando-os a todo o país.

\section{REFERÊNCIAS}

[s/n], CNIg prorroga concessão de visto humanitário aos haitianos. IN: Ministério do Trabalho, Brasília, 4 out. 2015. Disponível em: <http://trabalho.gov.br/noticias/1029cnig-prorroga-concessao-de-visto-humanitario-aos-haitianos>. Acesso em: 25 ago. 2016.

[s/n], Haitianos formam filas no Ministério do Trabalho para legalização na capital. IN: AC24HORAS, Rio Branco/AC, 14 maio 2014. Disponível em: <http://www.ac24horas.com/2014/05/14/haitianos-formam-filas-no-ministerio-dotrabalho-para-legalizacao-nacapital/?doing_wp_cron=1475607273.8897490501403808593750>. Acesso em: 25 ago. 2016.

[s/n], Sismo do Haiti de 2010. IN: Wikipédia, [s/d]. Disponível em: <https://pt.wikipedia.org/wiki/Sismo_do_Haiti_de_2010>. Acesso em: 14 ago. 2016.

[s/n]. Imigração haitiana no Brasil. IN: Wikipédia, [s/l], 2015. Disponível em: $<$ https://pt.wikipedia.org/wiki/Imigra\%C3\%A7\%C3\%A3o_haitiana_no_Brasil>. Acesso em: 25 ago. 2016.

[s/n]. VISTO HUMANITÁRIO PERMANENTE (VIPER Humanitário) E VISTO PERMANENTE A TÍTULO DE REUNIÃO FAMILIAR. IN: Embaixada do Brasil em Porto Príncipe. Disponível em: <http://portoprincipe.itamaraty.gov.br/ptbr/visto_permanente_humanitario_para_haitianos.xml>. Acesso em: 25 ago. 2016. 
BRASIL. Resolução Normativa CNIg no 97 de 12/01/2012. Publicado no DOU, em 13 jan. 2012. Dispõe sobre a concessão do visto permanente previsto no art. 16 da Lei oㅡ 6.815, de 19 de agosto de 1980, a nacionais do Haiti.

BRASIL. Sobre a situação jurídica do estrangeiro no Brasil - LEI № 6.815, DE 19 DE AGOSTO DE 1980. IN: PALÁCIO DO PLANALTO. Disponível em:

<http://www.planalto.gov.br/ccivil_03/leis/L6815.htm>. Acesso em: 25 ago. 2016.

BRASIL. Trabalho estrangeiro. IN: Ministério do Trabalho. Disponível em: <http://trabalho.gov.br/publicacoes-do-mtps/trabalho/trabalho-estrangeiro>. Acesso em: 25 ago. 2016.

LECH, Marcelo Mendes. MOREIRA, Luiz Carlos Lopes. Manual de Direito Internacional. 1. ed. Porto Alegre: Editora Ulbra, 2004.

LUFT, Celso Pedro. Minidicionário LUFT. 23. ed. São Paulo: Editora Ática, 2013.

MILESI, Rosita; TRAVIESO, Emilio (Org.). GUIA DE INFORMAÇÃO SOBRE TRABALHO AOS HAITIANOS. IN: CIBAI MIGRAÇÕES, 2012. Disponível em: $<$ http://www.cibaimigracoes.com.br/arquivos/guia_sobre_trabalho_aos_haitianos.pdf >. Acesso em: 25 ago. 2016. 